\title{
Hydrogen production from wood gasification promoted by waste eggshell catalyst
}

\begin{abstract}
Bio-hydrogen renowned as a future potential hydrogen source and studies were devoted in developing the efficient way to obtain the hydrogen. Biomass gasification of Azadirachta excelsa wood was carried out with addition of naturally derived $\mathrm{CaO}$ catalyst using temperature-programmed gasification (TPG) technique. The reaction (TPG) was performed at $50-1000^{\circ} \mathrm{C}$ in $5 \% \mathrm{O} 2 / \mathrm{He}$ with flow rate $10 \mathrm{ml} / \mathrm{min}$, and the product gas evolution $(\mathrm{H} 2, \mathrm{CH} 4$, $\mathrm{CO}$ and $\mathrm{CO} 2$ ) was detected by online mass spectrometer. The waste eggshell was chosen as a natural source of $\mathrm{CaO}$, and the effect of catalyst loading was investigated in this study. All the fresh and used catalysts were characterized, and the physicochemical changes of the eggshell were observed through scanning electron microscopy, X-ray fluorescence and X-ray diffraction techniques. Hydrogen yield were increased along with the catalyst loading (20\%, $40 \%$ and $60 \%$ ) from 57 to $73 \%$, respectively, compared to the reaction without catalyst. The additions of waste eggshell enhanced the catalytic activity and suppressed $\mathrm{CO} 2$ production through $\mathrm{CaO}$ absorption property which induced the water gas shift reaction that promotes $\mathrm{H} 2$ production at lower temperature.
\end{abstract}

Keyword: $\mathrm{CaO}$; Catalyst; Gasification; Hydrogen; Waste eggshell. 